\title{
ASPECTS OF ANAEROBIC METABOLISM IN ANODONTA CYGNEA L.
}

\author{
D. A. Holwerda and P. R. VeEnHOF \\ Vakgroep Scheikundige Dierfysiologie, Rijksuniversiteit Utrecht, Padualaan 8, 3508 TB Utrecht, \\ The Netherlands (Tel: 030-532578)
}

(Received 8 December 1983)

\begin{abstract}
After 6 days of anoxia $A$. cygnea had produced $1.0 \mu$ mole succinate, $2.7 \mu$ mole propionate and $1.7 \mu$ mole acetate $/ g$ of total soft tissue (wet). In addition, $0.35 \mu$ mole glutamate had disappeared. No other changes were detectable.

2. Concentrations of anaerobic end products and of amino acids differed from organ to organ. Large portions of all end products produced were present in the fluids within the animal.

3. Acetate and propionate were also excreted into the surrounding water.

4. In all tissues examined the activity ratio of pyruvate kinase and phosphoenolpyruvate carboxykinase was high

5. The $[\mathrm{PEP}]_{0.5}$ of pyruvate kinase was relatively low $(0.04-0.05 \mathrm{mM}$ at $\mathrm{pH} 7.5)$, and the enzyme is not strongly inhibited at decreased $\mathrm{pH}$ or in the presence of alanine.

6. Anaerobiosis influences this enzyme by decreasing the activity at low substrate concentration.
\end{abstract}

\section{INTRODUCTION}

The fresh water bivalve Anodonta cygnea L. can endure prolonged periods under anaerobic conditions. During winter the animal burrows in the mud of slow flowing rivers or ponds where it will encounter an environment of low oxygen content. In experimental conditions the mussel is able to withstand a gradually created anoxia for up to ten days at room temperature. A study relating the production of anaerobic metabolic end products in the whole animal has been made by Gäde et al. (1975). Meanwhile, more recent developments concerning pathways of anaerobic metabolism in molluscs (for a survey, see: Zandee et al., 1980) as well as regulatory aspects (Holwerda et al., 1981) have made it desirable to reassess the anaerobic metabolism of $A$. cygnea. Furthermore, we wished to see whether there is a tissue specificity in anaerobic metabolism. Zs.-Nagy (1977) suggested that a special type of anaerobic energy production may exist in tissues that are rich in pigment containing granula. The mechanism of this energy production would be an oxidative phosphorylation connected to an electron transfer chain that uses an endogenous hydrogen acceptor as a substitute for oxygen. These pigment-containing granula, termed cytosomes, are predominantly found in nervous tissue. Among the muscle tissues, the highest frequency of cytosomes is found in the heart muscle, whereas the adductor muscles contain few cytosomes or even none at all.

\section{MATERIALS AND METHODS}

\section{Animals}

Anodonta cygnea were collected from different locations in ponds near Utrecht. They were kept starved until needed in running tap water at $12^{\circ} \mathrm{C}$.

\section{Experimental procedures}

Animals were incubated anaerobically in tap water at $13^{\circ} \mathrm{C}(8 \mathrm{l} / \mathrm{kg}$ total body weight $)$ covered with a $2 \mathrm{~cm}$ layer of paraffin oil. Under these conditions the oxygen content of the water is consumed within one day. Excised organs were immediately frozen in liquid $\mathrm{N}_{2}$, and lyophilized. The enclosed water, together with the extrapallial fluid and probably part of the haemolymph, was filtered, made slightly alkaline by the addition of $\mathrm{NaOH}$, and concentrated by lyophilization. A sample of the incubation water was similarly treated.

For determination of metabolic changes the tissues were homogenized in $10 \mathrm{ml}$ per $\mathrm{g}$ dry weight of ice-cold $6 \%(\mathrm{w} / \mathrm{v})$ perchloric acid, using an Ultra-Turrax homogenizer. Valeric acid had been added to the mixture as an internal standard. After centrifugation at $50,000 \mathrm{~g}$ for $20 \mathrm{~min}$ the supernatants (perchloric acid extracts) were used for the assay of metabolites. For determination of enzyme activities and kinetics the dry tissues were homogenized in $50 \mathrm{mM}$ imidazole$\mathrm{HCl} / 2 \mathrm{mM} \quad \mathrm{MgSO}_{4} / 1 \mathrm{mM} \quad \mathrm{Na}_{2}$ EDTA/ $2 \mathrm{mM}$ dithioerythritol, $\mathrm{pH} 7.0$, at $0-5^{\circ} \mathrm{C}$. In the supernatant fraction enzyme activities of pyruvate kinase and phosphoenolpyruvate carboxykinase were measured. For the determination of kinetic parameters the supernatant was salted out according to Holwerda et al. (1981).

\section{Determination of metabolites}

L- and D-lactate were determined as described by Gutman and Wahlefeld (1974). Succinate was determined using a modified method based on the determination according to Kmetec (1966). Volatile fatty acids were assayed gaschromatographically according to Kluytmans et al. (1975). Free amino acids were analyzed as described by Zurburg and Kluytmans (1980). For isotachophoretic analysis the perchloric acid extract was neutralized with $\mathrm{K}_{2} \mathrm{CO}_{3}$ and percolated through Dowex $1 \times 2\left(\mathrm{OH}^{-}\right)$. The column was eluted with $4 \mathrm{M}$ formic acid. The eluate was lyophilized and the residue taken up into water. Analysis was carried out with the LKB 2127 Tachophor using $1 \mathrm{mM} \mathrm{HCl} / \beta$-alanine, $\mathrm{pH} 3.8$, as the leading electrolyte, and $10 \mathrm{mM}$ propionic acid $/ \beta$-alanine, $\mathrm{pH} 3.95$, as the terminating electrolyte.

\section{Determination of enzyme parameters}

Activities of phosphoenopyruvate carboxykinase and pyruvate kinase, and other kinetic parameters of the latter enzyme were determined essentially after Holwerda et al. (1981). Assay conditions for phosphoenolpyruvate car- 
Table 1. Differences of metabolite concentrations between control animals and animals after 6 days of anoxia in tissues and in fluids. Each value represents the difference between the mean of two groups of 5 animals. except for the heart where it concerns one group of 10 animals

\begin{tabular}{|c|c|c|c|c|c|c|}
\hline & Acetate & Succinate & Propionate & Aspartate & Glutamate* & Alanine \\
\hline & \multicolumn{6}{|c|}{$\Delta$ (anoxic-control) $\mu$ mole $/ g$ wet $w t$} \\
\hline Adductor muscles & 1.30 & 0.61 & 1.63 & -0.03 & 0.51 & 0.17 \\
\hline Mantle & 1.11 & 0.90 & 2.65 & 0.00 & -0.06 & 0.02 \\
\hline Gill & 0.89 & 0.57 & 1.86 & -0.03 & -0.08 & 0.02 \\
\hline Heart & 0.38 & 0.96 & 1.24 & 0.02 & -0.22 & 0.24 \\
\hline Rest & -0.18 & 0.62 & 0.98 & -0.05 & -0.45 & -0.01 \\
\hline $\begin{array}{l}\text { Enclosed water and } \\
\text { (part of) haemolympht }\end{array}$ & 1.26 & 0.39 & 0.83 & -0.01 & 0.01 & -0.01 \\
\hline $\begin{array}{l}\text { Incubation water of } \\
\text { the anoxic group }\end{array}$ & 0.33 & NP & 0.67 & ND & ND & ND \\
\hline
\end{tabular}

*Including glutamine; trotal amounts of metabolites divided by total weight of soft tissues; $\ddagger$ total amounts of the determined metabolites released by the anoxic animals, divided by total soft tissue weight; NP: not present; ND: not determined.

boxykinase were: $0.1 \mathrm{M}$ triethanolamine- $\mathrm{HCl} / 0.5 \mathrm{mM}$ $\mathrm{ZnCl}_{2} / 5 \mathrm{mM} \mathrm{KHCO}_{3} / 1.0 \mathrm{mM}$ IDP/2.0 mM PEP/0.2 mM $\mathrm{NADH} / 10 \mathrm{U}$ malate dehydrogenase, $\mathrm{pH} 7.0$, at room temperature. For pyruvate kinase: $0.1 \mathrm{M}$ imidazole- $\mathrm{HCl}$ / $8.3 \mathrm{mM} \mathrm{MgSO}_{4} / 67 \mathrm{mM} \mathrm{KCl} / 2 \mathrm{mM} \mathrm{ADP} / 5 \mathrm{mM}$ or variable $\mathrm{PEP} / 0.2 \mathrm{mM} \mathrm{NADH} / 5.5 \mathrm{U}$ L-lactate dehydrogenase, $\mathrm{pH}$ variable, at room temperature. Allosteric effectors were added as indicated in the text.

\section{RESULTS AND DISCUSSION}

\section{Anaerobic metabolic end products}

Table 1 comprises the main changes of metabolite levels in the different compartments. During 6 days (135 hr) of anoxia, A. cygnea accumulates acetate, succinate and propionate. Concentrations of $\mathrm{D}$ - and L-lactate were found to be very low in control animals and were not increased after the anoxic period (values not shown). The changes in the amino acid spectrum vary considerably among the individual tissues. In all organs the change of aspartate concentration is negligible, whereas glutamate (+glutamine) decreased significantly only in adductor muscle, heart and in the rest fraction. In heart and muscle tissue alanine concentrations increased, but except for heart there was no clear relationship found between the decrease of glutamate and increase of alanine level. Adductor muscle was also examined by isotachophoretic analysis for a possible change in the level of other metabolites. No changes were detected comparable to those of the three organic acids and the glutamate level. Products like strombine and alanopine which are found in marine mussels in the anoxic state or during recovery (Zandee et al., 1980) were especially looked for, but were not found to be present. Gäde and Grieshaber (1975) have already reported the absence of octopine formation in A. cygnea, in spite of a significant activity of octopine dehydrogenase in the adductor muscle.

The proportions of acetate, succinate and propionate accumulations are not constant in the respective compartments. This will probably be due to a differential release of the products into the internal fluids and the incubation water. From Table 2, in which the concentrations (Table 1) have been transformed into amounts ( $\mu$ moles per animal of mean weight), it can be seen that about $90 \%$ of the acetate produced has been released from the tissues. For propionate and succinate the values amount to 55 and $40 \%$, respectively. With respect to the tissue specificity, we found no indication suggesting a different type anaerobic metabolism in the heart, this being a tissue with a high content of cytosomes. On the contrary, the relatively high accumulation of succinate in the heart (Table 1) would not be expected if this organ relied on the mechanism of endogenous oxidation for energy production.

Table 2 further reveals that, although there remains some uncertainty in the values due to the discrepancy $( \pm 9 \%)$ between the overall mean animal weight (soft tissues) used in this table and the mean weight per subgroup, acetate on the one hand and succinate plus propionate on the other have been produced at a ratio of about 1 to 2 . From the

Table 2. Total change of metabolite amounts per organ/fluid after six days of anoxia. The values are obtained by multiplying the concentrations (Table 1) and the mean weight per organ in four subgroups or the mean total soft tissue weight for the fluids, respectively

\begin{tabular}{|c|c|c|c|c|c|}
\hline & Acetate & Succinate & Propionate & Glutamate* & Alanine \\
\hline & \multicolumn{5}{|c|}{$\Delta($ anoxic-control $) \mu$ mole/animal (mean weight) } \\
\hline Adductor muscles & 2.1 & 1.0 & 2.6 & -0.8 & 0.3 \\
\hline Mantle & 5.6 & 4.5 & 13.0 & -0.2 & 0.1 \\
\hline Gil! & 2.4 & 1.5 & 4.9 & -0.2 & $<0.1$ \\
\hline Heart & $<0.1$ & 0.1 & 0.2 & $<-0.1$ & $<0.1$ \\
\hline Rest & -47 & 15.7 & 24.7 & -11.6 & -0.4 \\
\hline $\begin{array}{l}\text { Enclosed water and } \\
\text { (part of) haemolymph }\end{array}$ & 47.6 & 14.7 & 31.4 & -0.3 & -0.5 \\
\hline $\begin{array}{l}\text { Incubation water of } \\
\text { the anoxic group }\end{array}$ & 12.3 & NP & 25.2 & ND & ND \\
\hline Sum & 65.4 & 37.5 & 102.0 & -13.2 & 0.3 \\
\hline
\end{tabular}

*Including glutamine; NP: not present; ND: not determined. 
experiments of Gäde et al. (1975), taking the situation after $30 \mathrm{hr}$ of anoxia, roughly the same value for the ratio of acetate to succinate + propionate can be calculated, although the excretion of the volatile acids into the incubation medium was not taken into account.

From a theoretical standpoint, and apart from questions of coenzyme specificity and subcellular compartmentation, the formation of acetate and succinate (including propionate) as end products of anaerobic glycolysis, in the recorded proportion, may result in a redox balance, as illustrated by the following equations:

glucose $\rightarrow 2$ acetate $+2 \mathrm{CO}_{2}+8 \mathrm{H}$

2 glucose $+4 \mathrm{CO}_{2}+8 \mathrm{H} \rightarrow 4$ succinate (or propionate $+\mathrm{CO}_{2}$ )

$+\frac{2 \text { glucose }+2 \mathrm{CO}_{2} \rightarrow 2 \text { acetate }+4 \text { succinate (or propionate }+\mathrm{CO}_{2} \text { ) }}{3}$.

The problem of the glycolytic pathway(s) will be discussed later in this section.

The change of the amino acid spectrum is confined to a decrease in the glutamate (glutamine) level. The participation of glutamate is rather small, and there seems to be no stoichiometric relation to the accumulation of the organic acids. As isotachophoretic analysis did not reveal accumulations of metabolites other than acetate, succinate and propionate, we may conclude that glutamate has been converted into succinate/propionate. Of course, although quantitatively not so important, as only $10 \%$ of the succinate/propionate production would derive from glutamate oxidation, the reducing equivalents (two moles of $\mathrm{NAD}(\mathrm{P}) \mathrm{H} /$ mole glutamate $\rightarrow$ succinyl- $\mathrm{CoA}$ ) from this pathway have to be taken into account when constructing a redox balance. The role of the glutamate conversion is still not clear, but two possibilities can be suggested. First, delivery of reduced NAD(P) could spark the reductive steps in the glycolytic pathway, namely the conversion of fumarate to succinate or the reductive carboxylation of pyruvate to malate, provided the latter reaction is indeed involved in the anaerobic pathway. Alternatively, formation of succinyl-CoA from glutamate might spark the conversion of succinate to propionate. For Mytilus edulis it is believed that the initiation of propionate production depends on the availability of succinyl-CoA through the oxoglutarate dehydrogenase step (Schulz et al., 1982). Once propionyl$\mathrm{CoA}$ has been formed, further production of succinyl-CoA would be achieved by means of the succinate:propionyl-CoA transferase reaction.

\section{Possible regulation at the PEP branchpoint}

The source of carbon for succinate formation may vary considerably among the invertebrates producing succinate and propionate as anaerobic end products. In muscle tissues of marine animals, e.g. body wall musculature of the lugworm Arenicola marina (Zebe, 1975; Felbeck and Grieshaber, 1980), the heart of the oyster Crassostrea gigas (Collicutt and Hochachka, 1977) and the adductor muscle of M. edulis (Ebberink et al., 1979), succinate is thought to be derived from aspartate, as the increase of the former corresponds to the decrease of the latter. In some freshwater invertebrates, e.g. larvae of the midge Chaoborus crystallinus (Englisch et al., 1982) and the leech
Hirudo medicinalis (Zebe et al., 1981), accumulation of succinate is accompanied by an equal decrease in an initially high concentration of malate. During prolonged anoxia, however, animals must rely on carbohydrate reserves, and then succinate (and propionate) will derive directly from carbohydrate breakdown (Holwerda and de Zwaan, 1980; Meinardus and Gäde, 1981).

On the basis of enzyme activities and kinetics (Holwerda and de Zwaan, 1973; Mustafa and Hochachka, 1973; Holwerda et al., 1981) and from experiments with metabolic inhibitors (Schöttler and

Wienhausen, 1981) it is presumed that the glycolytic pathway, up to phosphoenolpyruvate (PEP), and the reverse citric acid cycle reactions resulting in the formation of succinate, are linked by the action of PEP carboxykinase. We have investigated whether this pathway is also operative in $A$. cygnea. In the first place the ratio of maximal activities of pyruvate kinase and PEP carboxykinase was determined in three organs. In nerve tissue PEP carboxykinase activity was not detected at all. In adductor muscle and heart we found ratios of 38 and 90 , respectively. These values are considerably higher than those reported for $M$. edulis (de Zwaan, 1977), namely 3.6 and 8.7 for adductor muscle and heart, respectively.

We further determined kinetic parameters of pyruvate kinase. For $M$. edulis it was shown that during anoxia pyruvate kinase activity decreases through covalent modification (Holwerda et al., in press). The allosteric enzyme might be additionally inhibited by the increasing alanine level and a decreasing cellular pH (Holwerda and de Zwaan, 1973). In Table 3 values of $[\mathrm{PEP}]_{0.5}$ are compared for Mytilus and Anodonta. At the higher pH $[\mathrm{PEP}]_{0.5}$ of three tissues of Anodonta is still lower, by about 50\%, than the active variant of Mytilus adductor muscle. The effect of decreasing pH is much less in Anodonta than in Mytilus. The same holds for the effect of alanine. These findings fit well into the spectrum of end products. On the one hand concentrations of amino acids are very low in control animals and the level of alanine doesn't rise. On the other hand the excretion of large portions of the organic acids will protect the tissues from drastic acidification.

As a parameter for the covalent state of pyruvate kinase the ratio of activities at low substrate concentration $(0.05 \mathrm{mM}$ PEP) and at saturating concentration (1 mM PEP + $0.1 \mathrm{mM}$ fructose 1,6-biphosphate) can be taken. In M. edulis this ratio decreases for posterior adductor muscle from 0.20 to 0.13 after $8 \mathrm{hr}$ of anoxia, and for the mantle from 0.18 to 0.05 (Holwerda et al., in press). Especially for mantle, this reduction together with the effects of increasing alanine concentration and decreasing $\mathrm{pH}$ is believed to result in a shift at the PEP branchpoint towards carboxylation of phosphoenolpyruvate instead of formation of pyruvate. In Anodonta, after 6 days of anoxia, we measured a significant decrease of the 
Table 3. Comparison of $[\mathrm{PEP}]_{0.5}$ values of pyruvate kinase of some tissues of $A$. cvgnea with adductor muscle of $\boldsymbol{M}$. edulis; effects of $\mathrm{pH}$ and alanine

\begin{tabular}{llccc}
\hline \multirow{3}{*}{ Mytilus } & & \multicolumn{3}{c}{$[\mathrm{PEP}]_{0.5}(\mathrm{mM})$} \\
& Adductor muscle* & $\mathrm{pH} 7.5$ & $\mathrm{pH} 6.5$ & $\mathrm{pH} 6.9 / 2 \mathrm{mM}$ alanine \\
& Variant 1 & 0.09 & 0.28 & 0.86 \\
& Variant 2 & 0.17 & 0.94 & 2.6 \\
& & $\mathrm{pH} \mathrm{7.5}$ & $\mathrm{pH} \mathrm{6.6}$ & $\mathrm{pH} 6.6 / 2 \mathrm{mM}$ alanine \\
& Adductor muscle & 0.04 & 0.05 & 0.25 \\
& Heart & 0.05 & 0.07 & 0.47 \\
& Ganglia & 0.05 & 0.08 & 0.40 \\
\hline
\end{tabular}

*Holwerda et al. 1983.

ratio in all tissues examined (Fig. 1). However, in particular for the corresponding organs mantle and adductor muscle, the decrease is rather small: 0.40 to 0.30 and 0.42 to 0.33 , respectively. Therefore, the significance of pyruvate kinase inhibition might be found in a reduction of glycolytic flux during anaerobiosis rather than in a shift in the glycolytic pathway at the PEP branchpoint.

As can be seen in Fig. 1 the activity ratios of the well-pigmented heart muscle and the poorly pigmented adductor muscle differ considerably. This is especially true for the anoxic state. However, the strongly pigmented nervous tissue is just more

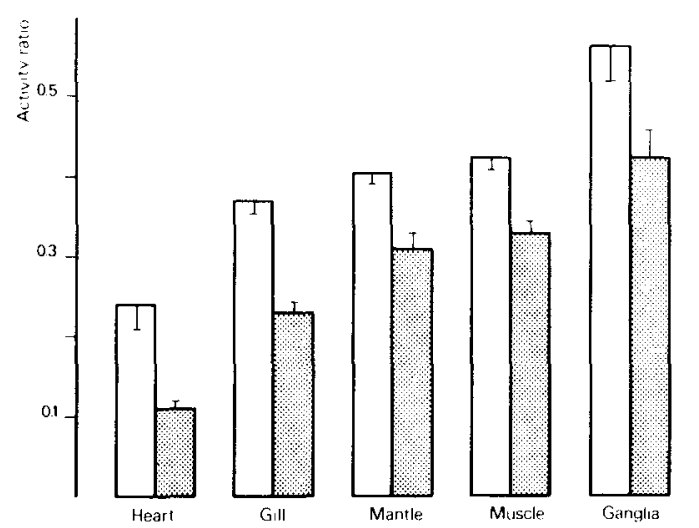

Fig. 1. Ratio of pyruvate kinase activities: $v(0.05 \mathrm{mM}$ PEP) $/ \mathrm{v}\left(1 \mathrm{mM}\right.$ PEP $+0.1 \mathrm{mM}$ fructose $\left.1,6-\mathrm{P}_{2}\right)$ in some organs of $A$. cygnea. Open bars: control animals (4 groups of 5 animals each, \pm SEM); dotted bars: after 6 days of anoxia (id., \pm SEM).

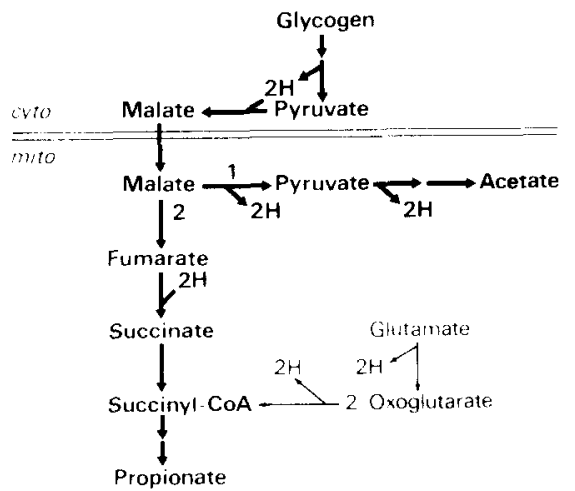

Fig. 2. Proposed metabolic pathways in A. cygnea in anaerobiosis. $\rightarrow$ : main pathway; $\rightarrow$ : minor pathway. differing from the heart with respect to the activity ratio. It is therefore clear that neither a tissue-specific spectrum of anaerobic end products nor the kinetic characteristics of pyruvate kinase provide an argument in favour of the hypothesis of anoxic endogenous oxidation as the mechanism for energy production in cytosome containing tissues.

\section{Anaerobic metabolic pathways}

Putting together the available information of PEP carboxykinase activity and kinetic parameters of pyruvate kinase we conclude that anaerobic glycolysis will not proceed via the $\mathrm{PEP} \rightarrow$ oxaloacetate step. Instead, pyruvate will be carboxylated to oxaloacetate or to malate. The latter alternative appears the more probable, as this reductive carboxylation could take place in the cytosol, thus ensuring cytoplasmic redox balance. Following transportation into the mitochondria malate would undergo dismutation to ultimately yield acetate and succinate/propionate. The feasibility of a malate dismutation has been demonstrated for Tubifex (Schöttler, 1977) and for Mytilus (de Zwaan et al., 1981). Two successive oxidative steps lead to the formation of acetyl-CoA and in one reductive step fumarate is converted into succinate. Thus, as already discussed in the first section, with a ratio $1: 2$ for the formation of acetate and succinate/propionate, redox balance is also maintained in the mitochondrion. The proposed pathways are shown in Fig. 2.

As mentioned previously, the non-stoiechiometric participation of glutamic acid and/or glutamine may have the function of triggering the formation of propionate from succinyl-CoA or, by means of delivery of reducing equivalents, of initiating the reductive step(s) in the pathway.

From the parameters for anaerobic metabolism used in this study we cannot derive arguments to support or to reject the hypothesis of anoxic endogenous oxidation. The metabolic potential of the cytosomes per se has to be examined in order to conclude whether these organelles participate in the anaerobic metabolism of $A$. cygnea.

\section{REFERENCES}

Collicutt J. M. and Hochachka P. W. (1977) The anaerobic oyster heart: coupling of glucose and aspartate fermentation. J. comp. Physiol. 115, 147-157.

Ebberink R. H. M., Zurburg W. and Zandee D. I. (1979) The energy demand of the posterior adductor muscle of Mytilus edulis in catch during exposure to air. Mar. Biol. Lett. 1, 23-31. 
Englisch H., Opalka B. and Zebe E. (1982) The anaerobic metabolism of the larvae of the midge Chaoborus crys tallinus. Insect Biochem. 12, 149-155.

Felbeck H. and Grieshaber M. K. (1980) Investigations on some enzymes involved in the anaerobic metabolism of amino acids of Arenicola marina L. Comp. Biochem. Physiol. 66B, 205-213.

Gäde G. and Grieshaber M. (1975) Partial purification and properties of octopine dehydrogenase and the formation of octopine in Anodonta cygnea L. J. comp. Physiol. 102, 149-158.

Gäde G., Wilps H., Kluytmans J. H. F. M. and Zwaan A. de (1975) Glycogen degradation and end products of anaerobic metabolism in the fresh water bivalve Anodonto cygnea. J. comp. Physiol. 104, 79-85.

Gutman I. and Wahlefeld A. W. (1974) L-(+)-lactate. In Methods of Enzymatic Analysis (Edited by Bergmeyer H. U.), pp. 1464-1468. Academic Press, New York.

Holwerda D. A., Kruitwagen E. C. J. and de Bont A. M. Th. (1981) Regulation of pyruvate kinase and phosphoenolpyruvate carboxykinase activity during anaerobiosis in Mytilus edulis L. Mol. Physiol. 1, 165-171.

Holwerda D. A., Veenhof P. R. and Zwaan A. de Physiological and biochemical investigations of the ecological relevance of anaerobiosis in bivalves. I-The change in activity of mussel adductur muscle and mantle pyruvate kinase during aerial exposure and reimmersion. Mar. Biol. Lett. (in press).

Holwerda D. A., Veenhof P. R., Van Heugten H. A. A. and Zandee D. I. (1983) Modification of mussel pyruvate kinase during anaerobiosis and after temperature acclimation. Molec. Physiol. 3, 225-234.

Holwerda D. A. and Zwaan A. de (1973) Kinetic and molecular characteristics of allosteric pyruvate kinase from muscle tissue of the sea mussel Mytilus edulis L. Biochim. biophys. Acta 309, 296-306.

Holwerda D. A. and Zwaan A. de (1980) On the role of fumarate reductase in anaerobic carbohydrate catabolism of Mytilus edulis L. Comp. Biochem. Physiol. 67B, 447-453.

Kluytmans J. H., Veenhof P. R. and Zwaan A. de (1975) Anaerobic production of volatile fatty acids in the sea mussel Mytilus edulis L. J. comp. Physiol. 104, 71-78.
Kmetec E. (1966) Spectrophotometric method for the enzyme microdetermination of succinic acid. Analyt. Biochem. 16, 474-480.

Meinardus G. and Gäde G. (1981) Anaerobic metabolism of the common cockle, Cardium edule. Comp. Biochem. Physiol. 70B, 271-277.

Mustafa T. and Hochachka P. W. (1973) Enzymes in facultative anaerobiosis of molluscs-III. Phosphoenolpyruvate carboxykinase and its role in aerobic-anaerobic transition. Comp. Biochem. Physiol. 45B, 657-667.

Schöttler U. (1977) NADH-generating reactions in anaerobic Tubifex mitochondria. Comp. Biochem. Physiol. 58B, 261-265.

Schöttler U. and Wienhausen G. (1979) The importance of the phosphoenolpyruvate carboxykinase in the anaerobic metabolism of two marine polychaetes. Comp. Biochem. Physiol. 68B, 41-48.

Schulz T. K. F., Kluytmans J. H. and Zandee D. I. (1982) In vitro production of propionate by mantle mitochondria of the sea mussel Mytilus edulis L.: overall mechanism. Comp. Biochem. Physiol. 73B, 673-680.

Zandee D. I., Holwerda D. A. and de Zwaan A. (1980) Energy metabolism in bivalves and cephalopods. In Animals and Environmental Fitness (Edited by Gilles R.), pp. 185-206. Pergamon Press, Oxford.

Zebe E. (1975) In vivo-Untersuchungen über den GlucoseAbbau bei Arenicola marina (Annelida, Polychaeta). $J$. comp. Physiol. 101, 133-145.

Zebe E., Salge U., Wiemann C. and Wilps H. (1981) The energy metabolism of the leech Hirudo medicinalis in anoxia and muscular work. J. exp. Zool. 218, 157-163.

Zs.-Nagy I. (1977) Cytosomes (yellow pigment granules) of molluscs as cell organelles of anoxic energy production. Int. Rev. Cytol. 49, 331-377.

Zurburg W. and Kluytmans J. H. (1980) Organ specific changes in energy metabolism due to anaerobiosis in the sea mussel Mytilus edulis L. Comp. Biochem. Physiol. 67B, 317-322.

Zwaan A. de (1977) Anaerobic energy metabolism in bivalve molluscs. Oceanogr. mar. Biol. Ann. Rev. 15, 103-187.

Zwaan A. de, Holwerda D. A. and Veenhof P. R. (1981) Anaerobic malate metabolism in mitochondria of the sea mussel Mytilus edulis L. Mar. Biol. Lett. 2, 131-140. 